\begin{tabular}{|c|c|c|c|c|c|c|}
\hline SES (high) & 0.13 & 0.27 & 0.22 & 0.6374 & 1.13 & $\begin{array}{c}0.67 \text { to } \\
1.91\end{array}$ \\
\hline Smoking & 0.91 & 0.19 & 21.83 & $<0.0001$ & 2.48 & $\begin{array}{c}1.69 \text { to } \\
3.63\end{array}$ \\
\hline BMI $\left(\mathrm{kg} / \mathrm{m}^{2}\right)$ & 0.00 & 0.00 & 0.01 & 0.9136 & 1.00 & $\begin{array}{c}1.00 \text { to } \\
1.00\end{array}$ \\
\hline $\begin{array}{l}\text { Constant } \\
\text { Epilepsy }\end{array}$ & -5.71 & 0.28 & 428.26 & $<0.0001$ & & \\
\hline Age & 0.01 & 0.00 & 10.50 & 0.0012 & 1.01 & $\begin{array}{c}1.01 \text { to } \\
1.02\end{array}$ \\
\hline Sex (female) & -0.16 & 0.14 & 1.43 & 0.2321 & 0.85 & $\begin{array}{c}0.66 \text { to } \\
1.11\end{array}$ \\
\hline FMF & -0.09 & 0.14 & 0.41 & 0.5216 & 0.92 & $\begin{array}{c}0.70 \text { to } \\
1.19\end{array}$ \\
\hline $\begin{array}{l}\text { SES } \\
\text { (medium) }\end{array}$ & -0.04 & 0.15 & 0.08 & 0.7769 & 0.96 & $\begin{array}{c}0.72 \text { to } \\
1.28\end{array}$ \\
\hline SES (high) & -0.34 & 0.21 & 2.49 & 0.1148 & 0.72 & $\begin{array}{c}0.47 \text { to } \\
1.09\end{array}$ \\
\hline Smoking & -0.03 & 0.15 & 0.03 & 0.8638 & 2.48 & $\begin{array}{c}1.69 \text { to } \\
3.63\end{array}$ \\
\hline BMI $\left(\mathrm{kg} / \mathrm{m}^{2}\right)$ & -0.01 & 0.01 & 0.24 & 0.6272 & 0.99 & $\begin{array}{c}0.97 \text { to } \\
1.02\end{array}$ \\
\hline Constant & -4.28 & 0.26 & 267.26 & $<0.0001$ & & \\
\hline
\end{tabular}
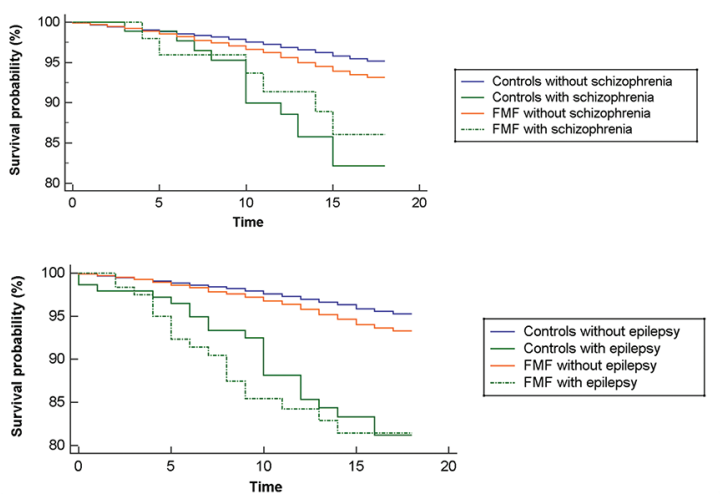

Figure 1. a+b. Kaplan-Meier survival plot of study cohorts

\section{Acknowledgement: None}

Disclosure of Interests: Kassem Sharif: None declared, Nicola Luigi Bragazzi: None declared, Abdulla Watad: None declared, Doron Comanesther: None declared, Arnon Cohen Grant/research support from: Prof. Arnon Cohen received research grants from Janssen, Novartis and AbbVie and Sanofi, Consultant for: Prof. Arnon Cohen served as a consultant, advisor for AbbVie; Amgen; Boehringer Ingelheim; Dexcel pharma; Janssen, Lilly; Neopharm; Novartis, Perrigo; Pfizer; Rafa; Sanofi

, Speakers bureau: Prof. Arnon Cohen served as speaker for AbbVie; Amgen; Boehringer Ingelheim; Dexcel pharma; Janssen, Lilly; Neopharm; Novartis, Perrigo; Pfizer; Rafa; Sanofi

, Dennis McGonagle Consultant for: Lilly, Novartis UCB, Speakers bureau: Lilly, Novartis UCB, Howard Amital Grant/research support from: Pfizer, AbbVie, Janssen, Grant/research support from: Pfizer, AbbVie, Janssen, Consultant for: Pfizer, Merck Sharp \& Dohme, Consultant for: Pfizer, Merck Sharp \& Dohme, Speakers bureau: Pfizer, Merck Sharp \& Dohme, Janssen, Sanofi, Bristol-Myers Squibb, Abbvie, Neopharm, Speakers bureau: Pfizer, Merck Sharp \& Dohme, Janssen, Sanofi, Bristol-Myers Squibb, Abbvie, Neopharm

DOI: 10.1136/annrheumdis-2019-eular.5788

\section{THU0688 ASSESSMENT OF THE QRISK2, QRISK3, SLE CARDIOVASCULAR RISK EQUATION, FRAMINGHAM AND MODIFIED FRAMINGHAM RISK CALCULATORS AS PREDICTORS OF CARDIOVASCULAR DISEASE EVENTS IN SYSTEMIC LUPUS ERYTHEMATOSUS}

Jagan Sivakumaran ${ }^{1,2}$, Paula Harvey ${ }^{3}$, Jiandong $\mathrm{Su}^{2}$, Ahmed Omar $^{4}$, Nicole Anderson ${ }^{2}$, Dafna D Gladman ${ }^{2,4}$, Murray B Urowitz ${ }^{2,4}$, Zahi Touma ${ }^{2,4}$. ${ }^{1}$ University of Toronto, Medicine, Toronto, Canada; ${ }^{2}$ Centre for Prognosis Studies in the Rheumatic Diseases, Rheumatology, Toronto, Canada; ${ }^{3}$ University of Toronto, Cardiology, Toronto, Canada; ${ }^{4}$ University of Toronto, Rheumatology, Toronto, Canada

Background: Systemic lupus erythematosus (SLE) is recognized as an independent risk factor for cardiovascular disease (CVD), and patients with SLE are at an elevated risk of CVD compared to the general population ${ }^{1}$. The complex interplay between conventional CVD risk factors, the inflammation caused by SLE and the pharmacological treatment of SLE contributes toward CVD risk ${ }^{1}$. Despite knowledge of this increased risk, there is no agreement on the use of risk assessment tools in the prediction of CVD in SLE. The Modified Framingham Risk Score (mFRS), QRISK3 and SLE Cardiovascular Risk Equation (SLECRE) have been introduced as promising CVD risk assessment tools considering SLE in prognosticating patients.

Objectives: To determine which cardiovascular risk assessment tool amongst the QRISK2, QRISK3, SLECRE, Framingham (FRS) and mFRS best predicts CVD events in SLE.

Methods: Single-centre analyses on prospectively collected data of 1887 SLE patients were performed to compute 10-year CVD risk scores for each tool. Tools' scores were evaluated against CVD events at or within ten years for cases (CVD events) and controls (no CVD events). For cases, the index date for risk score calculation was chosen 10 years, or as close to 10 years as possible prior to the CVD event. For controls, risk scores were calculated as close to 10 years as possible prior to the most recent clinic appointment. Proportions of patients classified as low $(<10 \%)$, median $(10-20 \%)$ and high risk $(>20 \%)$ of developing CVD according to each tool were determined. Sensitivity, specificity, positive/ negative predictive values and c-statistics of these tools were analysed. Results: 232 total CVD events were identified in the cohort including myocardial infarction, stroke, transient ischemic attack, heart failure and CVD death. QRISK2 and FRS risk-stratification was similar, while QRISK3 and mFRS risk-stratification was similar (Figure 1). The SLECRE classified the highest number of patients as median-high risk (Figure 1). The sensitivities and specificities are as follows for each tool: QRISK2 (19\%, 93\%), FRS $(22 \%, 93 \%)$, mFRS $(46 \%, 83 \%)$, QRISK3 $(47 \%, 78 \%)$, SLECRE $(61 \%$, $63 \%)$. The tools were similar in negative predictive value, ranging from $89 \%$ (QRISK2) to $92 \%$ (SLECRE). The FRS and mFRS had the greatest c-statistics, both equalling 0.73 , demonstrating the greatest predictive accuracy amongst the tools, while the QRISK3 had the lowest $(0.67)$.

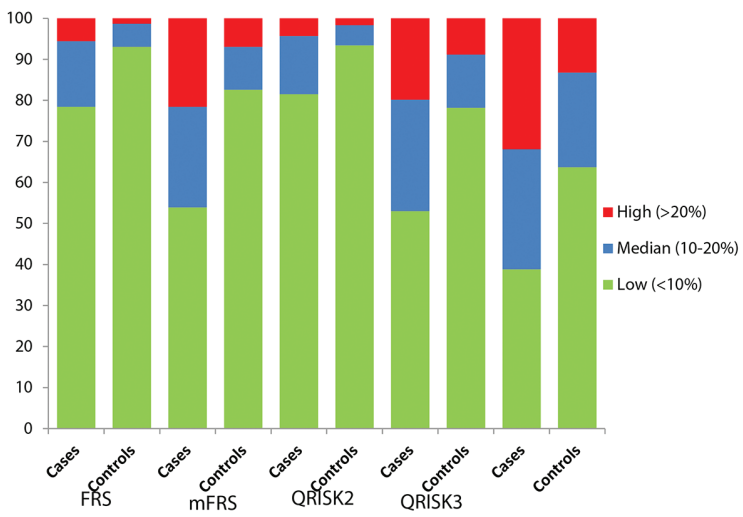

Figure 1. Percentage of patients considered low (<10\%), median (10-20\%) and high risk $(>20 \%)$ between cases (CVD, $n=232$ ) and controls ( $n o-C V D, n=1655$ ) according to the FRS, mFRS, QRISK2, QRISK3 and SLE CRE.

Conclusion: While the mFRS performance was superior to the FRS, the QRISK3 did not outperform the mFRS. Although the SLECRE had the highest sensitivity, it had the lowest specificity, demonstrated by grouping the most cases and controls in the median-high risk category. Several factors are important to consider when deciding which risk assessment tools to utilize: ease of use/computation, sensitivity/specificity, and laboratory data accessibility. Of the tools currently available, the mFRS is a practical tool with a simple, intuitive scoring system appropriate for the ambulatory clinic setting based on the initial weighting of the FRS while adjusting for SLE. However, much room for improvement exists in predicting CVD in SLE.

\section{REFERENCES :}

1. Hippisley-Cox, J., Coupland, C., \& Brindle, P. (2017). Development and validation of QRISK3 risk prediction algorithms to estimate future risk of cardiovascular disease: prospective cohort study. BMJ, 357, j2099.

Disclosure of Interests: Jagan Sivakumaran: None declared, Paula Harvey: None declared, Jiandong Su: None declared, Ahmed Omar: None declared, Nicole Anderson: None declared, Dafna D Gladman Grant research support from: AbbVie, Amgen, Celgene, Lilly, Novartis, Pfizer, 
and UCB, Consultant for: AbbVie, Amgen, BMS, Celgene, Galapagos, Gilead, Janssen, Lilly, Novartis, Pfizer, and UCB, Murray B Urowitz Grant/research support from: GSK, Consultant for: BMS, Celgene, GSK, Lilly, UCB, Zahi Touma Grant/research support from: GSK Canada, Consultant for: UBC, Pfizer, Janssen, Inc

DOI: 10.1136/annrheumdis-2019-eular.1146

\section{THU0689 1 ASTHMA AND ELEVATION OF ANTI-CITRULLINATED PROTEIN ANTIBODIES PRIOR TO THE ONSET OF RHEUMATOID ARTHRITIS}

Alessandra Zaccardelli ${ }^{1}$, Xinyi Liu ${ }^{1}$, Julia Ford ${ }^{1,2}$, Sara Tedeschi ${ }^{1,2}$, Jing Cui $^{1,2}$, Bing Lu ${ }^{1,2}$, Su Chu ${ }^{1,2}$, Peter Schur ${ }^{1,2}$, Cameron Speyer ${ }^{1}$, Karen Costenbader ${ }^{1,2}$, William Robinson ${ }^{3,4}$, Jeremy Sokolove ${ }^{3,4,5}$, Carlos Camargo, Jr. ${ }^{1,2} 6$,

Jeffrey Sparks ${ }^{1,2}$. 'Brigham and Women's Hospital, Boston, United States of America; ${ }^{2}$ Harvard Medical School, Boston, United States of America; ${ }^{3}$ Stanford University School of Medicine, Palo Alto, United States of America; ${ }^{4}$ VA Palo Alto Health Care System, Palo Alto, United States of America; ${ }^{5}$ Abbvie, Redwood City, United States of America; ${ }^{6}$ Massachusetts General Hospital, Boston, United States of America

Background: Anti-citrullinated protein antibodies (ACPA) are central to RA pathogenesis, with serum ACPA titers elevated years prior to clinical RA onset. Aberrant protein citrullination may occur in inflamed airway mucosa, forming neoantigens producing ACPA before articular involvement. Thus, individuals with inflammatory airway diseases, such as asthma, may be susceptible to RA-related autoimmunity.

Objectives: To investigate asthma as a risk factor for ACPA+ in serum prior to clinical RA onset.

Methods: We performed a cross-sectional analysis among women in the Nurses' Health Studies to examine whether asthma was associated with pre-RA ACPA+. Incident RA cases occurring after blood draw met research criteria and were each matched to 3 controls by age and menopausal status. Presence of self-reported asthma and potential confounders, including smoking pack-years, were assessed using questionnaires. The sensitive (primary) definition for ACPA+ was: $>3$ units on CCP2 or elevation ( $>99$ th percentile of the control distribution) on a research assay composed of autoantibodies targeting specific citrullinated protein epitopes. The specific (secondary) definition for ACPA+ was: $>5$ units on CCP2 or elevation of $\geq 2$ different antibodies to citrullinated proteins on the research assay. Logistic regression was used to obtain ORs for ACPA+ independent of confounders. We performed secondary analyses using the specific definition for ACPA+ and in subgroups restricted to never smokers and pre-RA cases.

Results: We measured ACPA on 1,135 women, including 286 pre-RA cases. Serum was banked a mean of 9.7 years (SD 5.8) prior to RA diagnosis, mean age of 51.9 years (SD 7.9). Overall, $12 \%$ of pre-RA cases reported asthma compared to $7 \%$ of controls; pre-RA cases were heavier smokers than controls. Of pre-RA cases, 96 (34\%) were ACPA+ by the sensitive definition and $60(21 \%)$ by the specific definition. Among the entire sample, women with asthma were more likely to have ACPA+ (unadjusted OR 2.51, $95 \% \mathrm{Cl} 1.42-4.44$ ) compared to those without asthma. After adjusting for age, smoking, BMI, and time to RA/matched date, asthma remained significantly associated with ACPA+ (OR 2.32, $95 \% \mathrm{Cl} 1.29-4.16)$. In the secondary analyses, we found similar associations of asthma with ACPA+ when using the specific definition for ACPA + (multivariable OR 2.28, 95\% $\mathrm{Cl} 1.11-4.69$ ) and when restricted to never smokers (OR $3.11,95 \% \mathrm{Cl} 1.29-7.47$ ) and only pre-RA cases (OR 2.22, $95 \% \mathrm{Cl} 1.01-4.88)$

Table: Odds ratios for elevated $\mathrm{ACPA}^{*}$ by asthma status at time of blood draw.

\begin{tabular}{|c|c|c|}
\hline & $\begin{array}{l}\text { Unadjusted } \\
\text { OR }(95 \% \mathrm{Cl})\end{array}$ & $\begin{array}{c}\text { Multivariable }{ }^{\star \star} \\
\text { OR }(95 \% \mathrm{Cl})\end{array}$ \\
\hline \multicolumn{3}{|c|}{ Entire sample $(n=1,135)$} \\
\hline No asthma & 1.00 (Ref) & 1.00 (Ref) \\
\hline Asthma & $2.51(1.42-4.44)$ & $2.32(1.29-4.16)$ \\
\hline \multicolumn{3}{|c|}{ Never smoker subset $(n=573)$} \\
\hline No asthma & 1.00 (Ref) & 1.00 (Ref) \\
\hline Asthma & $3.19(1.37-7.39)$ & $3.11(1.29-7.47)$ \\
\hline \multicolumn{3}{|c|}{ Pre- $R A$ case-only subset $(n=286)$} \\
\hline No asthma & 1.00 (Ref) & 1.00 (Ref) \\
\hline Asthma & $2.34(1.13-4.87)$ & $2.22(1.01-4.88)$ \\
\hline
\end{tabular}

${ }^{*}$ ACPA positivity (sensitive version) was defined as $>3$ units on the commercial CCP2 assay or $>99$ th percentile of control distribution on the research ACPA assay.

**Adjusted for age at blood draw, time to RA diagnosis/matched date for controls, BMI,

smoking pack-years (continuous, pack-years)

Conclusion: Asthma may be a novel risk factor for elevation of ACPA prior to RA onset, independent of smoking. These findings encourage further research on the contribution of airway inflammation to RA pathogenesis.

Disclosure of Interests: : Alessandra Zaccardelli: None declared, Xinyi Liu: None declared, Julia Ford: None declared, Sara Tedeschi: None declared, Jing Cui: None declared, Bing Lu: None declared, Su Chu: None declared, Peter Schur: None declared, Cameron Speyer: None declared, Karen Costenbader: None declared, William Robinson: None declared, Jeremy Sokolove Shareholder of: AbbVie, Employee of: AbbVie Carlos Camargo, Jr.: None declared, Jeffrey Sparks Grant/research support from: Bristol-Myers Squibb, Amgen, Consultant for: Optum DOI: 10.1136/annrheumdis-2019-eular.3107

\section{THU0690 DISEASE ACTIVITY CORRELATES WITH INSULIN RESISTANCE AND ADIPOCYTOKINES IN PATIENTS WITH DMARD-NAÏVE RHEUMATOID ARTHRITIS}

ali taylan ${ }^{1}$, Burak Toprak ${ }^{2}$, Baris Akinci ${ }^{3}$, Merih Birlik ${ }^{4}$, Fatma Demet Arslan², Baris Gundogdu ${ }^{5}$, Ayfer Colak ${ }^{2}{ }^{1}$ SBU Tepecik Egitim ve Arastirma Hastanesi, Rheumatology, izmir, Turkey, ${ }^{2} S B U$ Tepecik Egitim ve Arastirma Hastanesi, izmir, Turkey, ${ }^{3}$ Dokuz Eylul University School of Medicine, Department of Internal Medicine, Endocrinology, izmir, Turkey; ${ }^{4}$ Dokuz Eylul University School of Medicine, Department of Internal Medicine, Rheumatology, izmir, Turkey; ${ }^{5}$ Medeniyet University Department of Internal Medicine, Rheumatology, istanbul, Turkey

Background: Cardiovascular events such as myocardial infarction and stroke are frequent comorbidities in rheumatic diseases [1]. In relation, components of the metabolic syndrome (MS) including insulin resistance (IR), central obesity, high blood pressure, high triglycerides, and low highdensity lipoprotein (HDL) are related to a high rate of endothelial dysfunction and atherosclerosis in patients with RA [2]

Objectives: We aimed to investigate the relationship between disease activity and insulin resistance (IR) and the levels of adipocytokines in non-diabetic patients with newly diagnosed rheumatoid arthritis (RA) who are naïve to disease modifying anti-rheumatic drugs (DMARDs).

Methods: Forty-seven DMARD-naïve patients with RA and 25 age-, gender-, and BMI-matched controls were included. Erythrocyte sedimentation rate (ESR), C-reactive protein (CRP), 28-joint-count disease activity score (DAS28), serum lipids, glucose, HbA1c, insulin, leptin, resistin, visfatin, and RBP4 levels were measured. Homeostasis model assessment for insulin resistance (HOMA-IR) was calculated. Patients were studied before and 3 months after treatment with DMARDs.

Results: Levels of adipokines were similar in patients with RA and controls $(p>0.05$ for all). However, RA patients with active disease (DAS28 $>3.2)$ had numerically higher levels of leptin $(9.3(3.7-17.4)$ vs. 7.6 (3.7$11.0), p=0.289)$, insulin (8.0 (5.2-12.7) vs. 5.9 (4.2-8.7), $p=0.285)$, and HOMA-IR (1.9 (1.1-3.0) vs. $1.3(1.0-1.9), p=0.209)$. DAS28 was correlated with HOMA-IR $(r=0.356, p=0.016)$, insulin $(r=0.323, p=$ $0.02)$, and leptin $(r=0.399, p=0.005)$ in the study group (Figure-1) Regardless of the type of treatment modality, leptin levels (7.4 (4.4-13.4) vs. 6.4 (3.3-11.6, $\mathrm{p}=0.047)$ decreased significantly after treatment, as did insulin levels $(6.9(4.9-12.5)$ vs. $5.9(4.1-8.8), p=0.01)$ and HOMA IR score $(1.7(1.1-2.7)$ vs. $1.3(1.0-2.0), p=0.012)$. The reduction in leptin was more prominent in patients with active disease $(9.3$ (3.7-17.4) vs 6.9 (3.1-11.4), $\mathrm{p}=0.028)$. The reduction in ESR was correlated with $\triangle$ HOMA-IR $(r=0.308, p=0.039)$, and CRP reduction was correlated with $\Delta$ resistin $(r=0.288, p=0.049)$ and $\triangle R B P 4(r=0.456, p=0.001)$. Conclusion: Disease activity is associated with IR and correlates with circulating levels of adipokines in patients with RA. Treatment with DMARDs reduces leptin and improves IR.

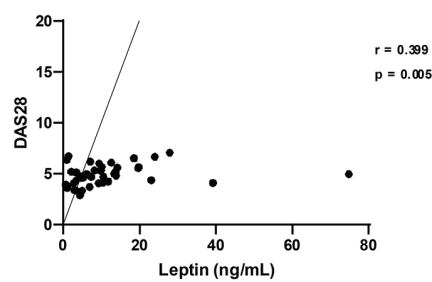




\section{REFERENCES:}

[1] Maradit-Kremers H, Crowson CS, Nicola PJ, Ballman KV, Roger VL, Jacobsen $\mathrm{SJ}$ et al. Increased unrecognized coronary heart disease and sudden deaths in rheumatoid arthritis: a population-based cohort study. Arthritis Rheum.2005; 52:402-11.

[2] Burggraaf B, van Breukelen-van der Stoep DF, de Vries MA, Klop B, van Zeben J, van de Geijn GM et al. Progression of subclinical atherosclerosis in subjects with rheumatoid arthritis and the metabolic syndrome Atherosclerosis. 2018; 271:84-91.

Disclosure of Interests: None declared

DOI: 10.1136/annrheumdis-2019-eular.3637

\section{THU0691 CLINICAL, RADIOLOGICAL, THERAPEUTIC ASPECT AND PROGNOSTIC OF INFECTIOUS SPONDYLODISCITIS WITHOUT BACTERIOLOGICAL EVIDENCE}

Rawdha Tekaya, Lobna Ben Ammar, Aicha Ben Tekaya, Khaoula Zouaoui, Olfa Saidane, Ines Mahmoud, Leila Abdelmoula. Charles Nicolle Hospital, Rheumatology, Tunis, Tunisia

Background: Early microbiological diagnosis and multidisciplinary management are the main predictive factor for successful treatment in septic spondylitis. However, the therapeutic management of spondylodiscitis without bacteriological diagnosis is not well codified.

Objectives: To evaluate whether there is clinical, biological or significant imaging between patients with infectious sondylodiscitis as they had or not a microbiological diagnosis.

Methods: Retrospective study including 107 patients hospitalized in our department between 1999 and 2018. The diagnosis was based on clinical, biological, radiological and bacteriological data.

Results: This study involved 107 patients, including 58 men (54.2\%) and 49 women $(45.8 \%)$ with a mean age of 55 years [16-86]. Spinal pain was observed in all cases and the lumbar spine was most affected (54.2\%). A neurological deficit was noted in $16.82 \%$ of cases. The inflammatory syndrome was present in $90.6 \%$ of cases. Radiographs of the spine were abnormal in $83.1 \%$ of cases. CT and Spinal MRI were performed respectively in $60 \%$ and $78.8 \%$ of cases. Disco vertebral biopsy was performed in 73 patients and was contributory in $46.5 \%$ of cases.

We divided patients into two groups: patients with a confirmed biological diagnosis (group 1: 45.3\%) versus patients in whom the diagnosis had been held on presumptive criteria (group2: $54.2 \%$ ). There was no statically significant difference in the age $(p=0.5)$, sex $(p=0.3)$, risk factors such as diabetes $(p=0.8)$, the start mode $(p=0.4)$, the presence of an impaired general condition $(p=0.3)$, night sweats $(p=0.1)$ and a neurological deficit $(p=0.8)$, biological parameters $(p=0.3)$ and the occurrence of complications $(p=0.09)$ between the two groups. Vertebral condensation in radiographs of the spine was higher in group 2 and this was statically significant $(\mathrm{p}=0.03)$. In addition, the consumption of unpasteurized milk and positivity of wright serology was higher in the first group ( $p=0.001$ and $p<0.001$; respectively). Similarly, contributive histological result of vertebral biopsy was more frequent in group $1(\mathrm{p}=0.007)$.

Conclusion: Diagnosing infectious spondylodiscitis is facilitated by improved access to MRI testing. However, microbiological diagnosis is the main key to a successful management of this life threatening infection. Disclosure of Interests: : None declared DOI: 10.1136/annrheumdis-2019-eular.8090

\section{THU0692 OCULAR MANIFESTATIONS IN BEHCET'S DISEASE MAY BE MORE COMMON IN CHILDREN THAN ADULTS: RESULTS OF A SYSTEMATIC REVIEW}

Matthew Turk ${ }^{1}$, Jacqueline Hayworth ${ }^{2}$, Tatiana Nevskaya ${ }^{1}$, Janet Pope ${ }^{1}$ ${ }^{1}$ University of Western Ontario, Rheumatology, London, Canada; ${ }^{2}$ University of Toronto, Toronto, Canada

Background: Behcet's disease (BD) can develop in both children and adults, but they may have different clinical features. Ocular involvement is common in BD and causes substantial impairment. The frequency of ocular involvement in $\mathrm{BD}$ has a wide range (5 to $89 \%$ ).
Objectives: This study determined the frequency and type of ocular manifestations in childhood and adult BD and compared prevalence of ocular manifestations by geographic location in those with $\mathrm{BD}$.

Methods: The protocol of ocular conditions in rheumatic conditions was registered at clintrials.gov (NCT03753893). Search terms were: conjunctivitis, keratoconjunctivitis sicca, xeropthalmia, uveitis, eye hemorrhage, optic neuritis, papilledema, orbital disease, retinal artery/vein occlusion, macular edema, retinitis, chorioretinitis, scleritis, iridocyclitits, choroid hemorrhage, blindness and amaurosis fugax in patients with BD. The search was performed with the assistance of an information specialist. Medline, Cochrane and Web of Science were used searching papers that spanned from their inception (1966, 1991 and 1990 respectively) to October 5, 2018. Studies were included if they had a minimum of twenty patients and reported the frequency of ocular manifestations within BD. Random effects models were used to combine the prevalence of ocular manifestations using Revman 5.3. Heterogeneity was evaluated using $\mathrm{I}^{2}$ and funnel plots.

Results: The search resulted in 3129 articles, of which 33 were included for meta-analysis. Eye manifestations were more frequent in childhood onset BD with the mean [95\% Confidence Interval] frequency of 50 [38$63] \%$ compared to 34 [25-43]\% in adults. In both children and adults, posterior uveitis (children $27 \%$ vs. adults $25 \%$ ) was the most common ocular manifestation, followed by anterior uveitis (children $18 \%$ vs. adults $23 \%$ ). When comparing the distribution of ocular manifestations in Behcet's in adults, there was geographic variation higher along the ancient Silk Road with ocular manifestations occurring in $40 \%$ of patients from Turkey and the Middle East. Ocular manifestations were similar in Europe $(36 \%)$ and North America (36\%), but less frequent in North Africa $(26 \%)$ and East Asia (20\%).

Conclusion: The frequency of ocular involvement is higher in children when compared to adults with $\mathrm{BD}$. The most common manifestation in the eyes is posterior and then anterior uveitis. Ocular involvement also presents regional differences.

\section{REFERENCES}

[1] Arevalo JF, Lasave AF, Al Jindan MY, Al Sabaani NA, Al-Mahmood AM, Al-Zahrani YA, et al. Uveitis in Behçet Disease in a Tertiary Center Over 25 Years: The KKESH Uveitis Survey Study Group. American Journal of Ophthalmology 2015;159:177-184.e2.

[2] Frigui M, Kechaou M, Jemal M, Ben Zina Z, Feki J, Bahloul Z. Optic neuropathy in Behçet's disease: a series of 18 patients. Rev Med Interne 2009;30:486-91.

[3] Keino H, Okada AA. Behçet's disease: global epidemiology of an Old Silk Road disease. Br J Ophthalmol 2007:91:1573-4.

[4] Leonardo NM, McNeil J. Behcet's Disease: Is There Geographical Variation? A Review Far from the Silk Road. International Journal of Rheumatology 2015;2015:1-7.

[5] Uva L, Miguel D, Pinheiro C, Filipe P, Freitas JP. Mucocutaneous manifestations of Behçet's disease. Acta Reumatol Port 2013;38:77-90.

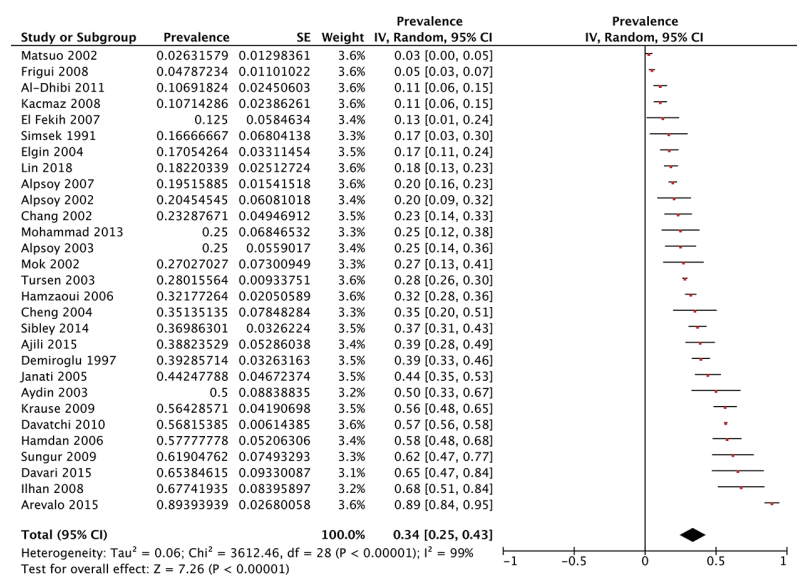

Figure: The prevalence (A) and geographic distribution (B) of ocular manifestations in adults with Behcet's disease. 